\title{
SÍNTESE E CARACTERIZAÇÃO DE NANOCOMPÓSITOS DE $\mathrm{AG} / \mathrm{TIO}_{2}$
}

\author{
M. E. B. DE SOUSA ${ }^{1}$, M. L. AGUIAR ${ }^{1}$ e P. F. R. REMIRO ${ }^{1}$ \\ ${ }^{1}$ Universidade Federal de São Carlos, Departamento de Engenharia Química \\ E-mail para contato: mariaelisaberriel@gmail.com
}

\begin{abstract}
RESUMO - Nas últimas décadas, houve um crescente interesse nos estudos da nanotecnologia, devido à expectativa que os nanomateriais podem causar na melhoria da qualidade de vida e na preservação do meio ambiente. Nesse contexto, esse estudo tem por objetivo sintetizar e caracterizar nanocompósitos de $\mathrm{Ag} / \mathrm{TiO}_{2}$, para serem aplicados em meios filtrantes utilizados em filtros comerciais empregados no condicionamento de ar de ambiente internos, para que possam atuar como agente biocida. Para identificar o método mais simples, eficaz e reprodutível, foram investigados quatro métodos de síntese: o método sol- gel proposto por Pan (2010); o Pan (2010) adaptado, no qual foi acrescentado uma etapa de calcinação; o método I, proposto pela autora, que consiste da síntese do $\mathrm{TiO}_{2}$ acrescentado à síntese de nanopartículas de prata; e o método II, também proposto pela autora, semelhante ao método I, mas na presença de um agente dispersante. Ao final, as amostras produzidas foram caracterizadas por Microscopia Eletrônica de Varredura (MEV) com Espectroscopia por Dispersão de Energia de Raios X (EDS). Através dos resultados obtidos concluiu-se que foi possível obter nanocompósitos de $\mathrm{Ag} / \mathrm{TiO}_{2}$ pelos quatro métodos estudados, mas o método Pan (2010) adaptado se mostrou mais eficaz, por possuir menor tempo de síntese e pela formação de nanopartículas de prata mais estáveis dispersas sobre uma matriz de dióxido de titânio através dos resultados do MEV.
\end{abstract}

\section{INTRODUÇÃO}

A grande área superficial das nanopartículas lhes conferem efeitos mais pronunciados e, dentre esses efeitos, a ação bactericida de alguns metais, como prata e titânio, permite que nanopartículas e nanocompósitos de metais tenham grande potencial para atuarem como agentes antibacterianos em diversas áreas, como na indústria alimentar, desinfecção de água, ar e de outros campos relacionados.

A ação antibacteriana da prata é conhecida desde a antiguidade, contudo, o alto custo de obtenção desse material impede sua maior utilização no combate a microrganismos e infecções. $\mathrm{O}$ uso desse material em escala nanométrica, além de mais eficaz em sua ação contra microrganismos, reduziria a quantidade de material utilizado (Yu et al, 2011). Dióxido de titânio $\left(\mathrm{TiO}_{2}\right)$ é um dos fotocatalisadores mais eficazes atualmente em uso, devido ao seu forte poder oxidante, a sua não-toxicidade e estabilidade física e química a longo prazo. É relatado que a combinação com nanopartículas de prata aumenta expressivamente a atividade fotocatalítica de $\mathrm{TiO}_{2}$. Sendo assim, nanocompósitos $\mathrm{Ag} / \mathrm{TiO} \mathrm{O}_{2}$ possuem a vantagem de 
pronunciar a função antibacteriana do nanomaterial para uma ampla gama de condições de trabalho (ZHAO; KOZUKA; YOKO, 1996).

Neste contexto, este trabalho teve como proposta sintetizar e caracterizar nanocompósitos de $\mathrm{Ag} / \mathrm{TiO}_{2}$, para serem aplicados em filtros de ar. A finalidade dessa investigação é, posteriormente, utilizar esses meios filtrantes modificados em equipamentos de condicionamento de ar, em ambientes internos, para minimizar os bioaerossís (bactérias e fungos) presentes no material particulado de ambientes internos.

\section{MÉTODOS}

As sínteses dos nanocompósitos $\mathrm{Ag} / \mathrm{TiO}_{2}$ foram feitas através de quatro métodos diferentes a fim de compará-los e testar suas reprodutividades e eficiências. Nos itens seguintes serão descritas as quatro sínteses realizadas.

\subsection{Método proposto por Pan (2010)}

Pan (2010) obteve bons resultados na síntese de nanocompósitos de $\mathrm{Ag} / \mathrm{TiO}_{2}$ pelo método sol-gel, realizando os testes da seguinte forma: $5 \mathrm{~mL}$ de butóxido de titânio (IV) $(0,014 \mathrm{~mol})$ foram adicionados a $9,6 \mathrm{~mL}$ de ácido acético $(0,16 \mathrm{~mol})$ com agitação contínua. Foram dissolvidos $0,121 \mathrm{~g}$ de nitrato de prata $(0,000712 \mathrm{~mol}$, de modo que a proporção em mols $\mathrm{Ag} / \mathrm{Ti}=0,05)$ em $30 \mathrm{~mL}$ de água duas vezes destilada após a adição de $0,9 \mathrm{~g}$ de goma arábica. A mistura foi aquecida a $60^{\circ} \mathrm{C}$ por $30 \mathrm{~min}$ para dissolver completamente o agente dispersante (goma arábica). A solução foi então resfriada a temperatura ambiente e foi adicionada gota-a-gota à solução contendo butóxido de titânio, mantendo agitação constante.

Citrato de sódio foi usado como agente redutor a uma concentração de $0,4 \mathrm{M}$ e volume de $3,56 \mathrm{~mL}$, que foi adicionado à solução sobre vigorosa agitação e misturado por 3 horas a $60^{\circ} \mathrm{C}$. Um igual volume de etanol foi adicionado para precipitar pó de $\mathrm{TiO} 2$ da suspenção coloidal e a solução foi filtrada. O sobrenadante foi removido e $25 \mathrm{~mL}$ de álcool etílico foram adicionados para suspender e lavar o filtrado coloidal. O produto coloidal foi centrifugado a $4500 \mathrm{rpm}$ por $30 \mathrm{~min}$, o sobrenadante foi removido, $5 \mathrm{~mL}$ de água destilada foram adicionados e o coloide foi novamente centrifugado a $4500 \mathrm{rpm}$ por $30 \mathrm{~min}$. O produto coloidal foi então lavado um total de 3 vezes com etanol e água.

\subsection{Método Pan (2010) adaptado}

O método Pan (2010) adaptado foi baseado no método descrito por Pan (2010), com a seguinte modificação: após a adição do agente redutor (concentração de $0,4 \mathrm{M}$ e volume de $3,56 \mathrm{~mL}$ ) à solução sobre vigorosa agitação e misturado por 3 horas a $60^{\circ} \mathrm{C}$, a solução foi calcinada para evaporar os materiais orgânicos. A calcinação foi feita em uma mufla a $400^{\circ} \mathrm{C}$ por $1 \mathrm{~h}$ em um cadinho de alumina previamente tratado (tratamento termico a $1000^{\circ} \mathrm{C}$ por 30min). Em seguida, o material foi desaglomerado por moagem em almofariz e foi feito um peneiramento em peneira de malha $200(74 \mathrm{~mm})$ e o cadinho foi colocado novamente na mufla a $900{ }^{\circ} \mathrm{C}$ por mais $2 \mathrm{~h}$, a uma razão de aquecimento de $10^{\circ} \mathrm{C} / \mathrm{min}$.

\subsection{Método I proposto pela autora}


Para o preparo do nanocompósito de $\mathrm{AgTiO}_{2}$, nanocompósitos de dióxido de titânio foram adicionados à síntese da nanopartícula de prata, de modo que foi formado $\mathrm{Ag} / \mathrm{TiO}_{2}$. Os métodos descritos a seguir foram baseados nos procedimentos descritos por Câmara (2004), Zoccal (2010) e Turkevich et al (1951).

A síntese do nanocompósito de dióxido de titânio descrita a seguir faz parte do método do percursor polimérico, também chamado método Pechini: $62,5 \mathrm{~g}$ de ácido cítrico foram disssolvidos em $250 \mathrm{~mL}$ de água, sob agitação constante e aquecimento em um agitador magnético a $70{ }^{\circ} \mathrm{C}$ e $500 \mathrm{rpm}$ e um volume de $31,7 \mathrm{~mL}$ de isopropóxido de titânio foi dissolvido nessa solução em cotas de $10 \mathrm{ml}$, obtendo-se uma solução límpida e estável que foi deixada sob agitação e aquecimento por 1,5h. Em seguida, o aquecimento foi encerrado, agitou-se a solução por mais $3 \mathrm{~h}$ e a quantidade de titânio foi gravimetricamente determinada.

A gravimetria foi feita em um cadinho de alumina previamente tratado (tratamento termico a $1000^{\circ} \mathrm{C}$ por $30 \mathrm{~min}$ ), no qual foram adicionados $5 \mathrm{~mL}$ da solução de citrato de titânio e foi levado a uma chapa de aquecimento a $120^{\circ} \mathrm{C}$ para evaporar o solvente remanescente e foram adicionados $8,53 \mathrm{~mL}$ de etilenoglicol para promover a polimerização. O aquecimento foi mantido até que o volume caísse pela metade, formando uma resina, que foi lavada para calcinação em uma mufla a $400^{\circ} \mathrm{C}$ por 1 horas. Em seguida, o material foi desaglomerado por moagem em almofariz e foi feito um peneiramento em peneira de malha $200(0,074 \mathrm{~mm})$ e o cadinho foi colocado novamente na mufla a $900{ }^{\circ} \mathrm{C}$ por mais $2 \mathrm{~h}$, a uma razão de aquecimento de $10^{\circ} \mathrm{C} / \mathrm{min}$. $\mathrm{O}$ nanomaterial $\mathrm{TiO}_{2}$ apresentou a forma de um pó sólido branco.

Para a síntese da nanopartícula de prata, foi utilizado o método de Turkevich, através da redução de nitrato de prata com citrato de sódio: em $125 \mathrm{~mL}$ de água de uma solução $1 \mathrm{mM}$ de AgNO3, foram adicionados 0,19965g de TiO2, de modo que a relação TiO2/Ag foi 20/1. Essa solução foi colocada em aquecimento de $100^{\circ} \mathrm{C}$ e agitação a 1100 e $5 \mathrm{~mL}$ de citrato de sódio $(0,04 \mathrm{M})$ foram gotejados por cerca de $5 \mathrm{~min}$. Em seguida, o aquecimento foi encerrado e a agitação foi mantida por mais $5 \mathrm{~min}$.

\subsection{Método II proposto nessa pesquisa}

O método II seguiu o mesmo procedimento do método I, mas com a adição de um agente dispersante na síntese da nanopartícula de prata (método de Turkevich): em $125 \mathrm{~mL}$ de água de uma solução $1 \mathrm{mM}$ de $\mathrm{AgNO}_{3}$, foram adicionados $0,00419 \mathrm{~g}$ do dispersante (que equivale a $2,5 \%$ da massa total) e $0,02125 \mathrm{~g}$ de $\mathrm{TiO}_{2}$. Essa solução foi colocada em aquecimento de $100^{\circ} \mathrm{C}$ e agitação a 1100 e $5 \mathrm{~mL}$ de ácido cítrico foram gotejados por cerca de $5 \mathrm{~min}$. Em seguida, o aquecimento foi encerrado e a agitação foi mantida por mais $5 \mathrm{~min}$.

\section{RESULTADOS}

A caracterização das amostras foi feita através da Microscopia Eletrônica de Varredura (MEV) com Espectroscopia por Dispersão de Energia de Raios X (EDS) no Laboratório de Caracterização Estrutural (DEMa/ UFSCar). A Figura 1 mostra as imagens obtidas pelo MEV (FEI Inspect S 50 e Philips XL-30 FEG) dos resultados dos quatro métodos estudados. Os equipamentos apresentaram uma limitação na visualização da escala nanométrica, contudo foi possível identificar pequenas partículas, principalmente no método I, no qual essas pequenas partículas aparentam ter aproximadamente $50 \mathrm{~nm}$. 
Figura 1. MEV das amostras obtidas pelos métodos: (1) método proposto por Pan (2010); (2) Pan (2010) adaptado; (3) método I; (4) método II.
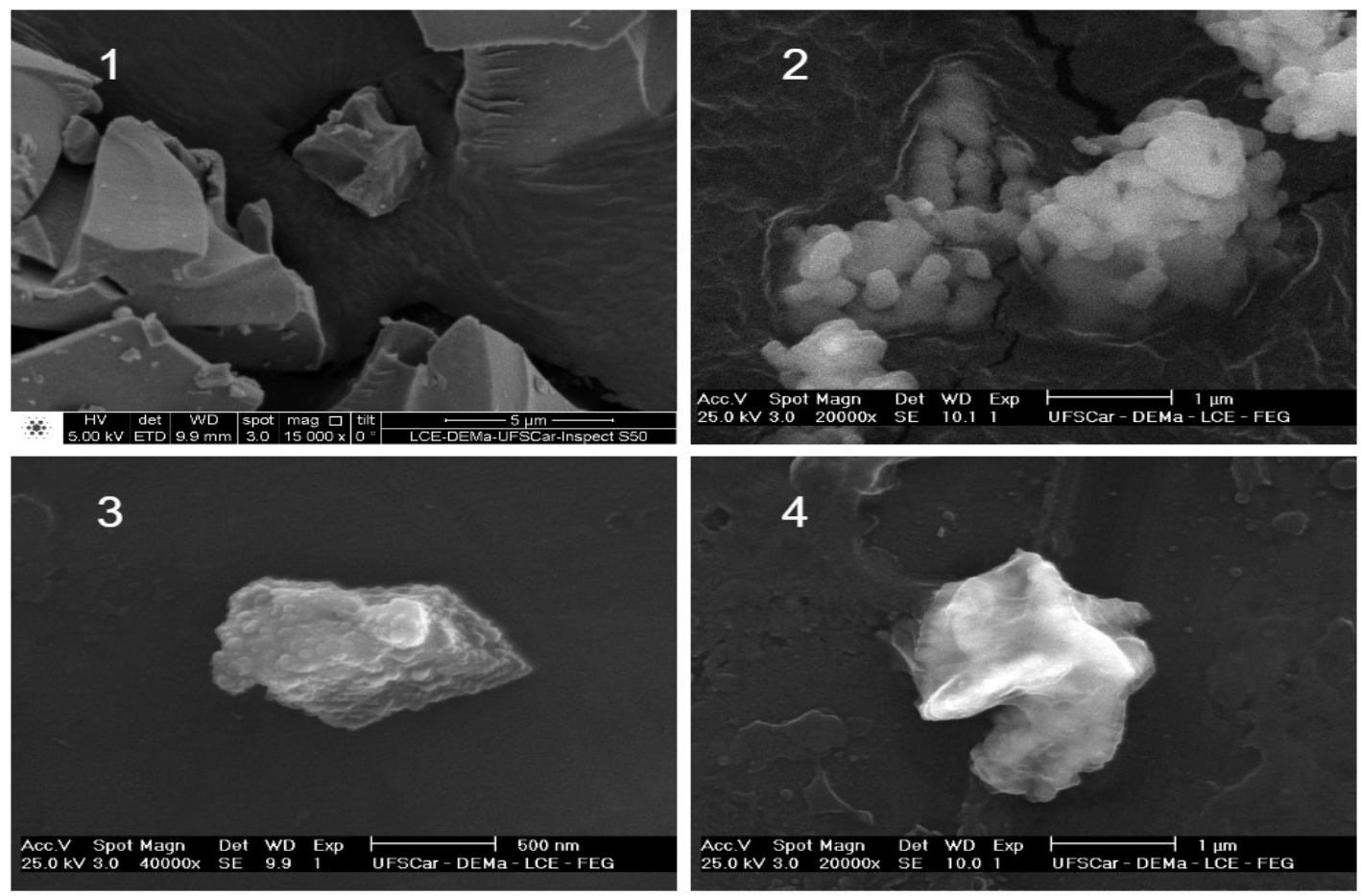

Figura 2. Imagem da linha de composição da amostra do método proposto por Pan (2010) (1) e imagens do EDS das amostras obtidas nas sínteses: (2) Pan (2010) adaptado; (3) método I; (4) método II.
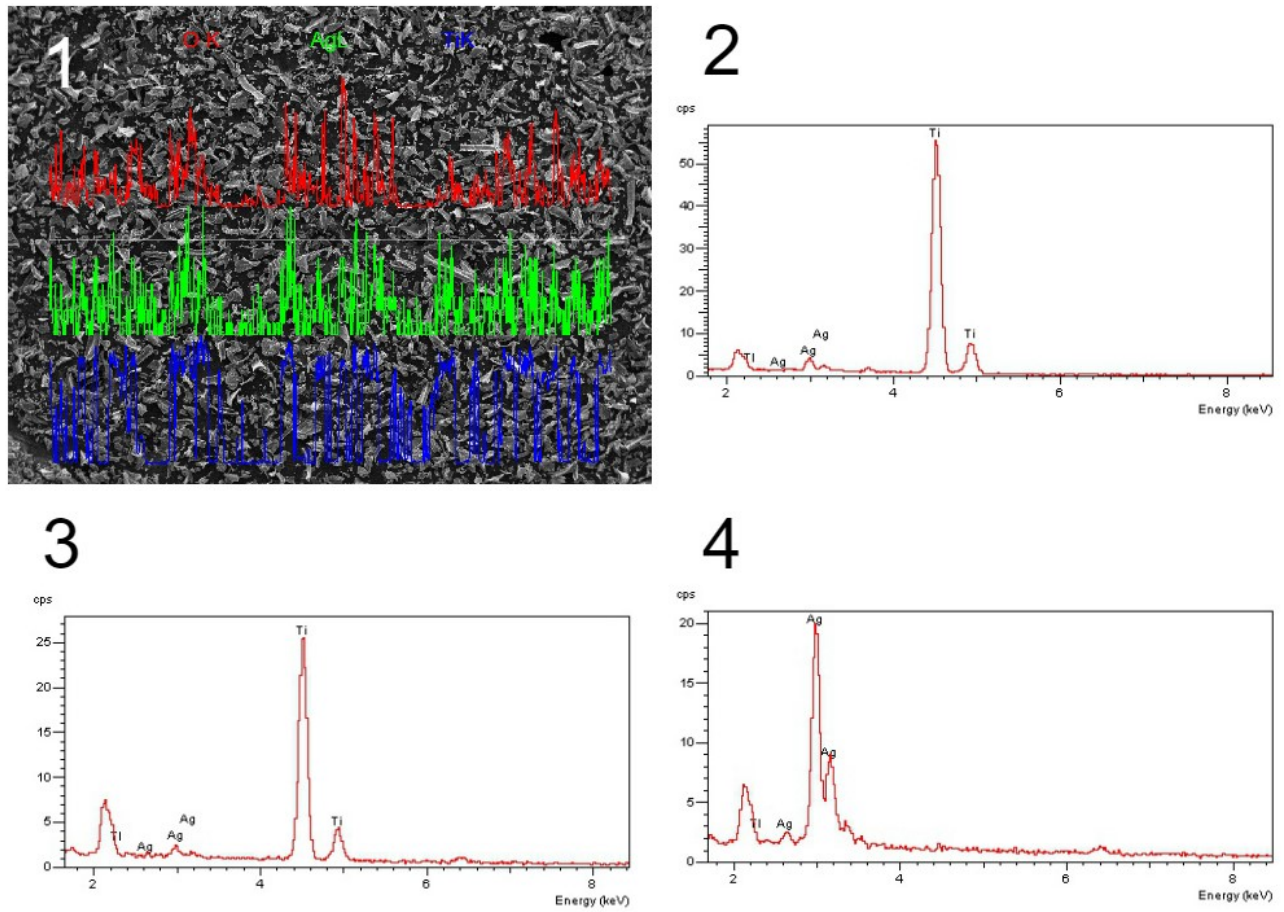


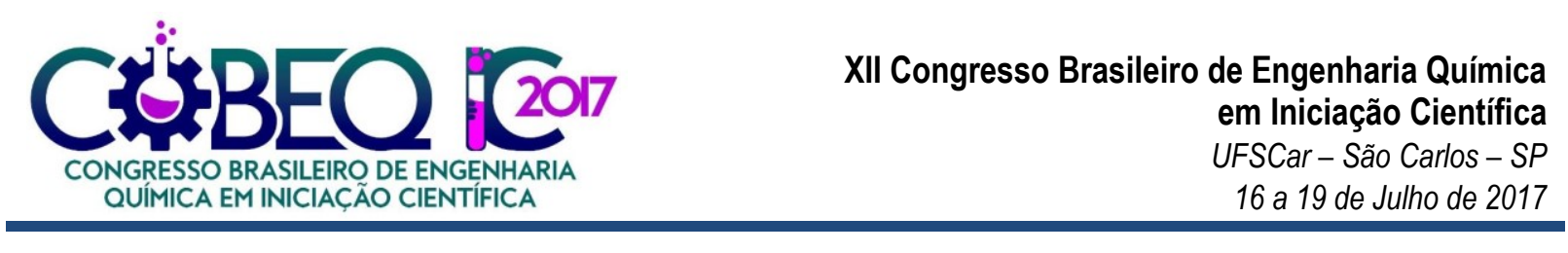

Os resultados da Espectroscopia por Dispersão de Energia de Raios X (EDS) e da linha de composição mostrados na Figura 2 permitiram identificar os elementos químicos presentes na amostra e, assim, confirmar que o nanocompósito $\mathrm{Ag} / \mathrm{TiO}_{2}$ foi sintetizado, pois, para todos os métodos, a linha de composição e o EDS indicaram que as amostras foram constituídas principalmente de titânio, oxigênio e prata.

Apenas com o aparelho FEI Magellan 400 L foi possível chegar na escala nanométrica com boa resolução. Com esse equipamento, foram feitas análises de $\mathrm{TiO}_{2}$ sintetizado pelo método Pechini e $\mathrm{Ag} / \mathrm{TiO}_{2}$ sintetizado pelo método Pan (2010) adaptado. A Figura 3 indica que a amostra de $\mathrm{TiO}_{2}$ era constituída de partículas menores que $70 \mathrm{~nm}$ até partículas maiores que 300nm. Já na Figura 4 é possível identificar partículas de $\mathrm{Ag} / \mathrm{TiO}_{2}$ com tamanhos em uma faixa de aproximadamente 60 até $120 \mathrm{~nm}$. Além disso, nessa mesma figura em maior escala (à esquerda), o $\mathrm{TiO}_{2}$ parece formar uma matriz que se assemelha à Figura 3 e, nessa matriz estão dispersas as nanopartículas de prata.

Figura 3. Dióxido de Titânio em nanoescala.

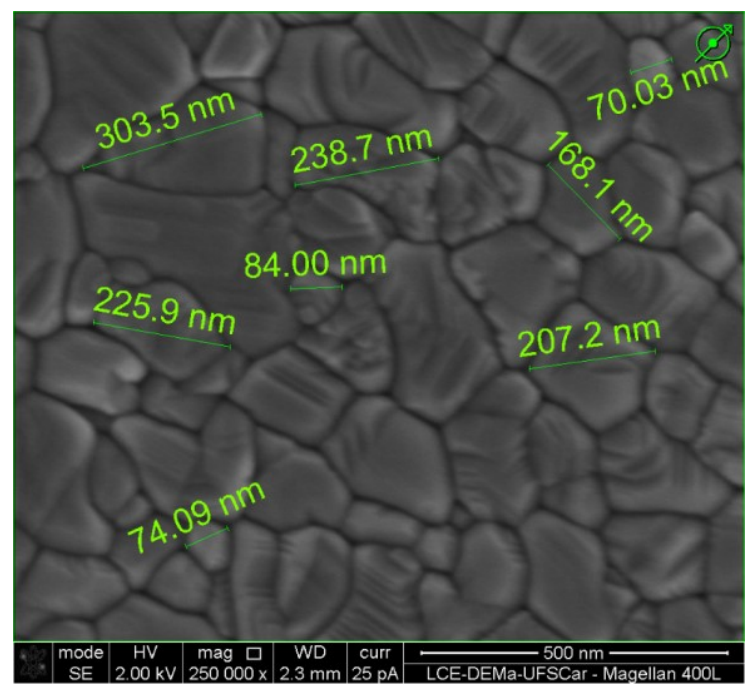

Figura 4. Nanocompósito Ag-TiO2 em micro e nanoescala.

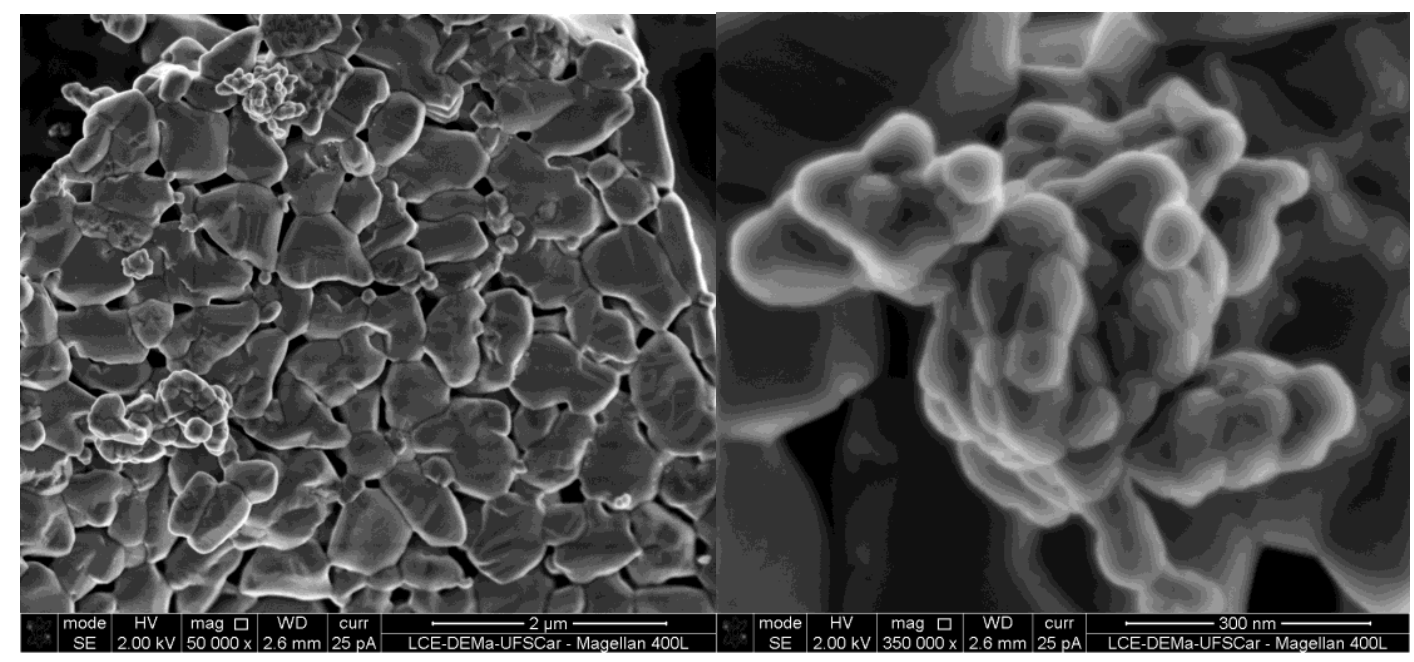




\section{CONCLUSÃO}

Os resultados permitiram concluir que os nanocompósitos de $\mathrm{Ag} / \mathrm{TiO}_{2}$ foram conseguidos pelos quatro métodos estudados, pois a linha de composição e o EDS indicaram que as amostras foram constituídas principalmente de titânio, oxigênio e prata. Além disso, o MEV indicou partículas de $\mathrm{Ag} / \mathrm{TiO}_{2}$ menores que $500 \mathrm{~nm}$ na amostra do método I, partículas com tamanhos em uma faixa de aproximadamente 60 até $120 \mathrm{~nm}$ no método Pan (2010) adaptado e partículas de $\mathrm{TiO}_{2}$ entre 70 e $300 \mathrm{~nm}$, sintetizadas pelo método Pechini.

Dentre os quatro métodos, o método Pan (2010) adaptado se mostrou mais interessante por possuir menor tempo de síntese, por ter se mostrado ser facilmente reprodutível e pela formação de nanopartículas de prata dispersas sobre uma matriz de dióxido de titânio observadas através dos resultados do MEV.

\section{REFERÊNCIAS}

CÂMARA, M. S. C. da. Síntese e caracterização a nível nanométrico da fase Li2 (M) Ti3O8, $M=Z n$, Co e Ni pelo método Pechini. 2004. 114p.Tese (Doutorado) - Universidade Federal de São Carlos, São Carlos, 2004.

PAN, X. et al. Nanocharacterization and bactericidal performance of silver modified titania photocatalyst. Colloids and Surfaces B: Biointerfaces, v. 77, n. 1, p. 82-89, 2010.

TURKEVICH, J et al.. A study of the nucleation and growth processes in the synthesis of colloidal gold. Discuss. Faraday Soc 11, 55-75.

ZHAO, G.; KOZUKA, H.; YOKO, T. Sol-gel preparation and photoelectrochemical properties of TiO2 films containing Au and Ag metal particles. Thin Solid Films, v. 277, n. 1, p. 147-154, 1996.

ZOCCAL, J. V. M. Sintese e caracterização de nanopartículas de TiO2 pelo método do precursor polimérico. 2010. 94 f. Dissertação (Mestrado em Engenharia Química) Universidade Federal de São Carlos, São Carlos, 2010.

YU, B. et al. Synthesis of $\mathrm{Ag}-\mathrm{TiO} 2$ composite nano thin film for antimicrobial application. Nanotechnology, IOP PUBLISHING, v. 22, n. 11, p. 1-9, 2011. Dispinível em: <stacks.iop.org/Nano/22/115603> Acesso em: abr, 2015. 